\title{
Microcogeneration with Stirling Engine and Solar Power: Energetic Balance in Mediterranean Climate
}

\author{
Juan A. Auñon ${ }^{1}$, Mariano Sidrach De Cardona ${ }^{2}$, José M. Pérez ${ }^{1}$ and Javier Aranceta ${ }^{3}$ \\ 1. Department of Mechanical, Thermal and Fluids Engineering, Campus of Teatinos Universidad de Málaga, Málaga 29071, Spain \\ 2. Department of Applied Phisycs II. E.I.I., Campus of Teatinos, Universidad de Málaga, Málaga 29071, Spain \\ 3. CS Centro Stirling S. Coop, Avda. Álava, 3, Aretxabaleta (Gipuzcoa), 20550, Spain
}

\begin{abstract}
This paper analyzes the viability of a new microcogeneration system with a Stirling engine micro-CHP (combined heat and power) and renewable solar energy: thermal and photovoltaic system, using accumulation system for hot water and ion lithium batteries for electricity. A weather station gives real meteorological parameters for Mediterranean climate (Málaga, Spain). A control unit permits to have a full automated system, which works according to a flowchart. This controller also allows theorizing a demand profile curve of daily consumption, typical for this or other climates. Many studies analyse different kinds of combined systems by simulating or making the real installation to obtain results for either microcogeneration or solar power, but not together, e.g. central heating applications to obtain a constant consumption of hot water. This new system shows a new combination of resources (natural gas in Stirling and solar energy systems), and the implementation allows doing experiments with different profiles of consumption to have real, non-theoretical, results. The control system is self-governing: it connects the different supplies of energy (solar thermal, photovoltaic, Stirling or batteries) depending on the demand, this demand can be changed by simulating any profile: domestic (heat and power), business, low thermal demand, low electricity demand, etc.
\end{abstract}

Key words: Microcogeneration, Stirling engine, solar energy, photovoltaic system.

\section{Nomenclature}

$$
\begin{aligned}
& \varepsilon_{\text {gas }}=\text { Gas energy }(\mathrm{Wh}) \\
& \varepsilon_{\mathrm{p}}=\text { Produced energy }(\mathrm{Wh}) \\
& \varepsilon_{\mathrm{pn}}=\text { Used energy }(\mathrm{Wh}) \\
& \varepsilon_{\mathrm{PV}}=\text { PV Energy }(\mathrm{Wh}) \\
& \varepsilon_{\mathrm{rad}}=\text { Solar radiation }(\mathrm{Wh}) \\
& \varepsilon_{\mathrm{th}}=\text { Thermal energy }(\mathrm{Wh}) \\
& \eta_{\mathrm{pv}}=\text { PV efficiency } \\
& \eta_{\mathrm{s}}=\text { System efficiency } \\
& \eta_{\mathrm{sn}}=\text { System net efficiency } \\
& \eta_{\mathrm{th}}=\text { Thermal efficiency } \\
& \mathrm{CO}_{2 \mathrm{r}}=\mathrm{CO}_{2} \text { emissions reduction }(\%)
\end{aligned}
$$

\section{Introduction}

Nowadays, sustainable energy policies are reducing energy consumption in buildings and producing the required energy in a more efficient way than few years

Corresponding author: Juan A, Auñon, Ph.D., associate professor, research fields: stirling engine, internal combustion engine. ago. Moreover, the reduction of costs of solar energy systems, especially significant photovoltaic systems (PV), allow cost effective alternatives to conventional energy systems.

There are technologies such as micro-cogeneration that have been improving during the last years, since they work with many functional and economic advantages over the conventional kinds of production.

Stirling engine based micro-CHP devices have been analysed during last years and are becoming a solution for supplying heating, domestic hot water (DHW) and electrical power such as González-Pino et al. concluded [1,2]. Valenti and Silva [3] compared the alone micro-CHP unit in experimental and numerical analyses of the device. Improving the performance of a micro-CHP device is related with keeping a constant heat demand since when electricity is produced you can take advantage of the heat that is also being produced [4] and that is why "District Heating" is a 
trend as studied by Emmanouil Malliotakis et al. [5]. In application to energy production, Karmacharya and Putrus [6] go further in a simulation with multiple micro-generators: a micro-CHP device supported with a wind turbine and a photovoltaic panel.

The proposed system has Stirling engine like novelty in cogeneration systems combined with renewable energy. Without this engine, there are many studies about cogeneration. "Trigeneration for domestic purposes in isolated areas based on hybrid RES" Acevedo et al. [7] made an analysis about this systems published in International Conference on Renewable Energies and Power Quality (ICREPQ'17). With focus in rural applications, Jan Iwaszkiewicz et al. [8] published "A Practical Approach to the Cogeneration System for Rural Appliances". Similar focus than this work has the article "Design and Operation of a Local Cogeneration Plant Supplying a Multi-family House" published by M. Fernandez et al. [9], in this case for $9.5 \mathrm{~kW}$ electricity and $35 \mathrm{~kW}$ thermic power. A cogeneration system with thermal engine and photovoltaic was analysed by M. Dondas [10] in fuel consumption minimization of a cogeneration system multi machines associated with a photovoltaic.

\section{Material and Methods}

The laboratory of cogeneration in Málaga University (Fig. 1) has three systems for energy production and storage.

The micro-cogeneration consists of a Whispergen EU1 Stirling micro-CHP unit, a solar thermal system with two solar collectors and one $300 \mathrm{~L}$ associated water storage tank. The solar collectors are installed in a parallel circuit to the Stirling hot water production. One photovoltaic system has $3.0 \mathrm{~kW}$ peak power with an electrical storage of $48 \mathrm{~V}$ lithium-ion battery and $10 \mathrm{kWh}$ of capacity. The entire electrical system is controlled by a photovoltaic inverter Sun Storage 1play 3TL. The electrical part of the micro-CHP unit is also connected to the inverter.

It is also able to connect to the grid, only if it is necessary, and has the Stirling as auxiliary electrical source.

The technical characteristics of the systems are summarized in Table 1.

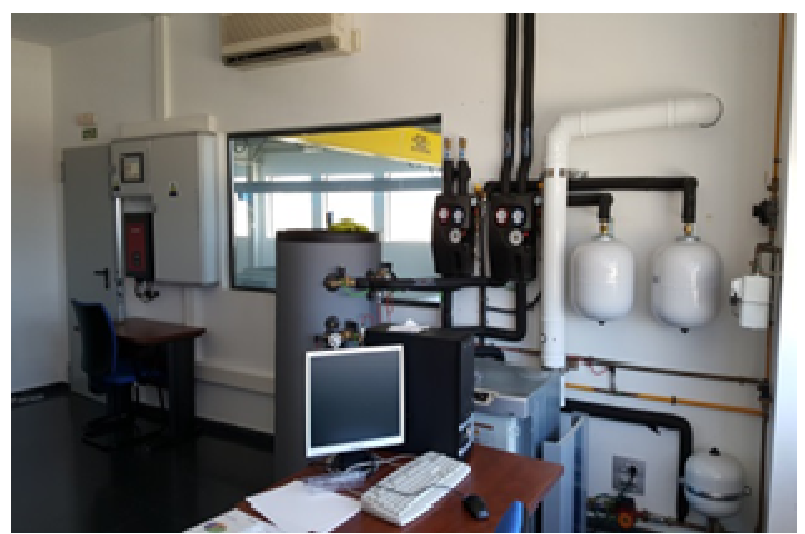

Fig. 1 Cogeneration laboratory facilities.

Table 1 Technical characteristics of the system.

\begin{tabular}{lc}
\hline & Stirling micro-CHP \\
\hline Model & Whispergen EU1 \\
Engine & 4 Cylinders double acting Stirling cycle \\
Electrical output & Up to $1 \mathrm{~kW}$ \\
Thermal output & Up to $7 \mathrm{~kW}$ \\
Fuel consumption & $1.55 \mathrm{~m}^{3} / \mathrm{h}$ \\
\hline & Solar thermal system \\
\hline Collector model & Chromagen \\
Collector area & $3.54 \mathrm{~m}{ }^{2}$ \\
Recommended flow & $45 \mathrm{~L} / \mathrm{h} \cdot \mathrm{m}^{2}$ \\
Maximum pressure & $10 \mathrm{bar}$ \\
Storage tank capacity & $300 \mathrm{~L}$ \\
\hline & Ingeteam Sun Storage 1play 3TL \\
\hline Inverter model &
\end{tabular}


Table 1 to be continued

\begin{tabular}{lc}
\hline & Storage system connection \\
\hline Voltage rank & $48-300 \mathrm{~V}$ \\
Maximum charge/discharge & $50 \mathrm{~A}$ \\
\hline & Photovoltaic connection \\
\hline Voltage rank & $300-450 \mathrm{~V}$ \\
Maximum intensity & $20 \mathrm{~A}$ \\
\hline & Consumption connection \\
\hline Maximum permanent power & $3,000 \mathrm{~W}$ \\
Maximum intensity & $13 \mathrm{~A}$ \\
Performance & \\
Maximum efficiency & $95.5 \%$ \\
Euroefficiency & $95 \%$ \\
\hline & Accumulation system \\
\hline Battery model & LG Chem Resu $10 \mathrm{Li}-\mathrm{Io}$ \\
Nominal voltage & $51.8 \mathrm{~V}$ \\
Voltage range & $42.0-58.8 \mathrm{~V}$ \\
Usable energy & $8.8 \mathrm{kWh}$ \\
Capacity & $189 \mathrm{Ah}$ \\
\hline & Photovoltaic system \\
\hline Nominal peak power & $3,000 \mathrm{Wp}$ \\
Nominal power of the modules & $245 \mathrm{Wp}$ \\
Module efficiency & $15.04 \%$ \\
Intensity of maximum power & $8.33 \mathrm{~A}$ \\
Voltage of maximum power & $29.37 \mathrm{~V}$ \\
\hline
\end{tabular}

A weather station measures real time data of the solar irradiation, ambient temperature, humidity, wind speed and direction, as well as the photovoltaic module temperature.

A control system based on a PLC Mitsubishi model L02CPU-P with an interface GT2510-VTBA commands the whole system and manages the production and the activation of the loads according to a provided flowchart, which allows simulating any demand profile in electrical or thermal energy. The operating data of all the systems in real time are recorded. Fig. 2 shows the diagram of the experimental system.

The system works according to an established flowchart. This flowchart allows optimizing the use of renewable sources and saving gas consumption. In this way, the micro-CHP is an auxiliary source for both the thermal and photovoltaic system.

\section{Theory/Calculation}

This work shows the results of a representative day, after analysis of many different days: sunny, half-overcast or overcast, in Mediterranean climate (Malaga city, Spain). Different demand profiles are also analysed to compare the system behaviour in this conditions.

The main parameters for analysis are solar irradiance $\left(R_{S}\right)$ and demand profile. Fig. 3 shows a typical profile for sunny and half-overcast days with the irradiance values in Málaga.

Figs. 4 and 5 show profiles for electrical and thermal demand. The electrical demand is typical for a house with Spanish timetable, with maximum demand after 19.00 and around 14.00 for working days.

For the system analysis, these concepts are defined:

$$
\text { PV efficiency }\left(\eta_{\mathrm{pv}}\right) \eta_{P V}=\frac{P V \text { energy }\left(\varepsilon_{P V}\right)}{\operatorname{Solar~Radiation}\left(\varepsilon_{r a d}\right)}
$$

Thermal efficiency $\left(\eta_{\text {th }}\right) \eta_{t h}=\frac{\text { Thermal Energy }\left(\varepsilon_{t h}\right)}{\text { Solar Radiation }\left(\varepsilon_{\text {rad }}\right)}$ 


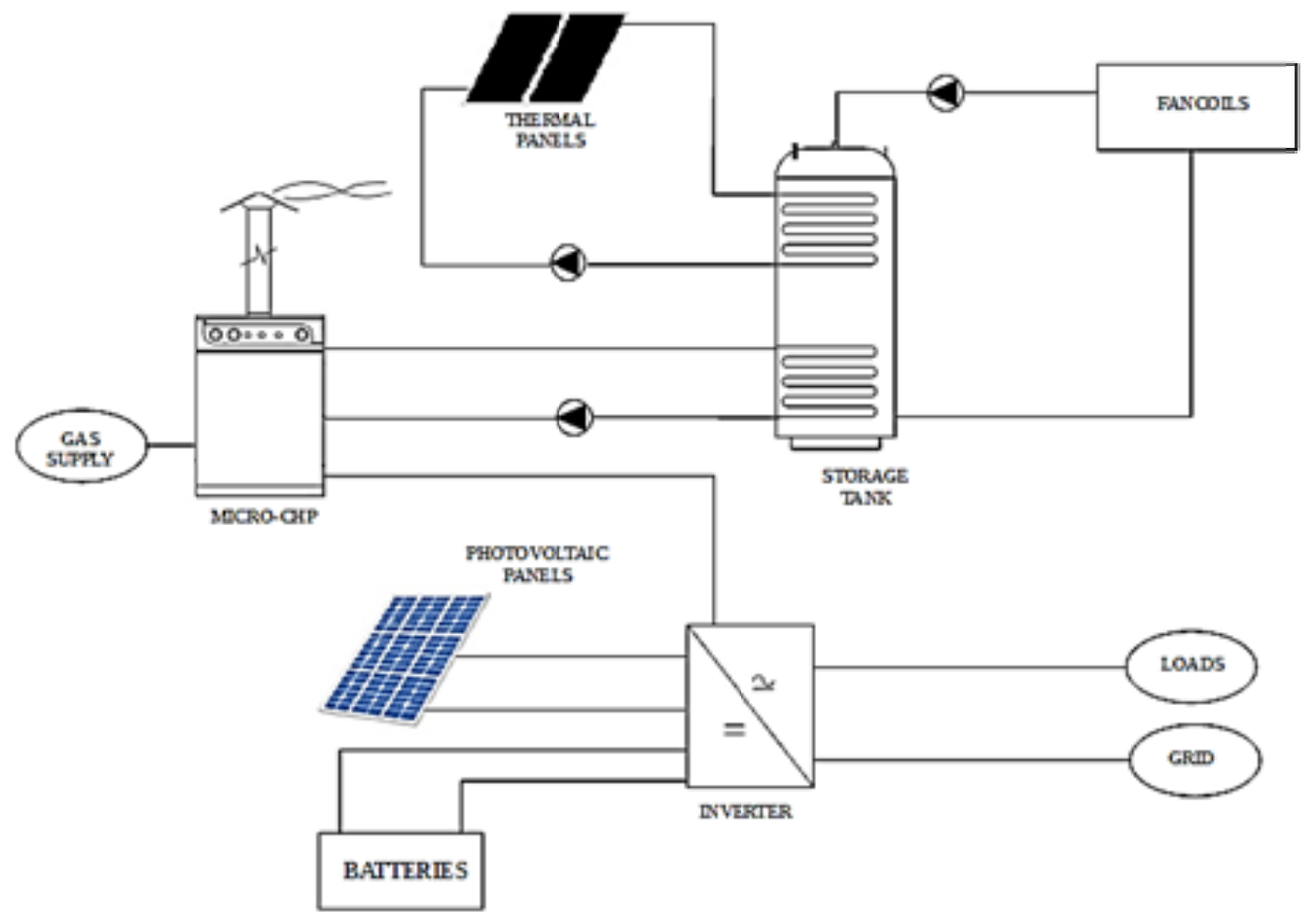

Fig. 2 Diagram of the experimental system.

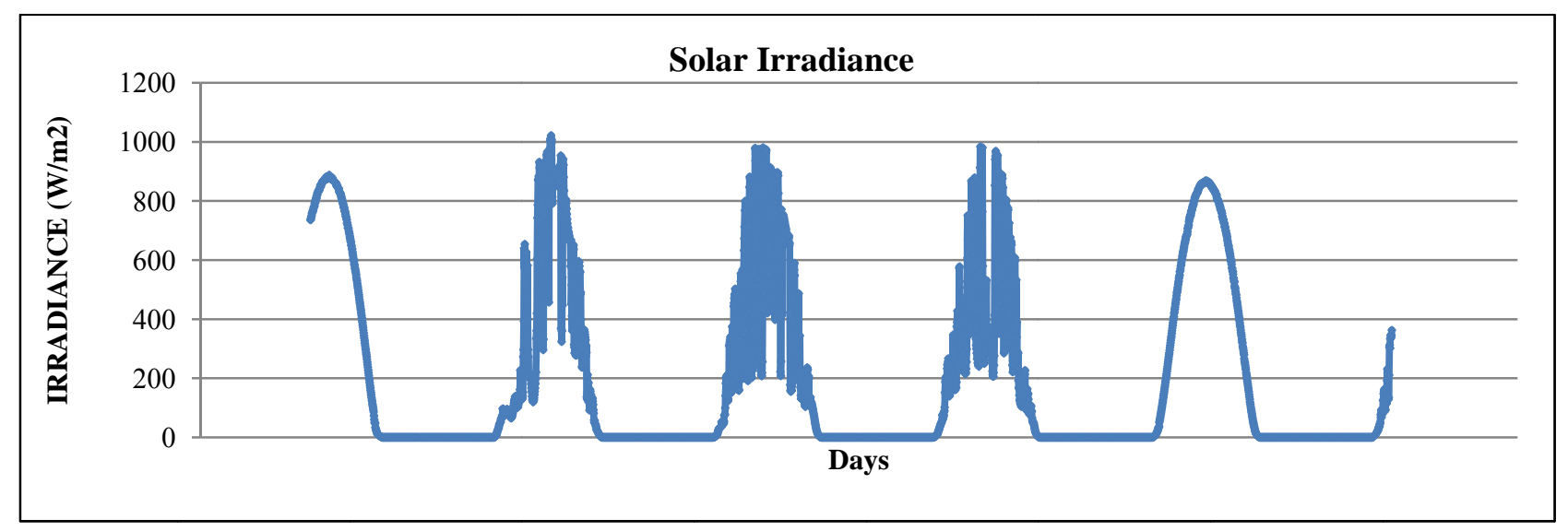

Fig. 3 Solar irradiance.

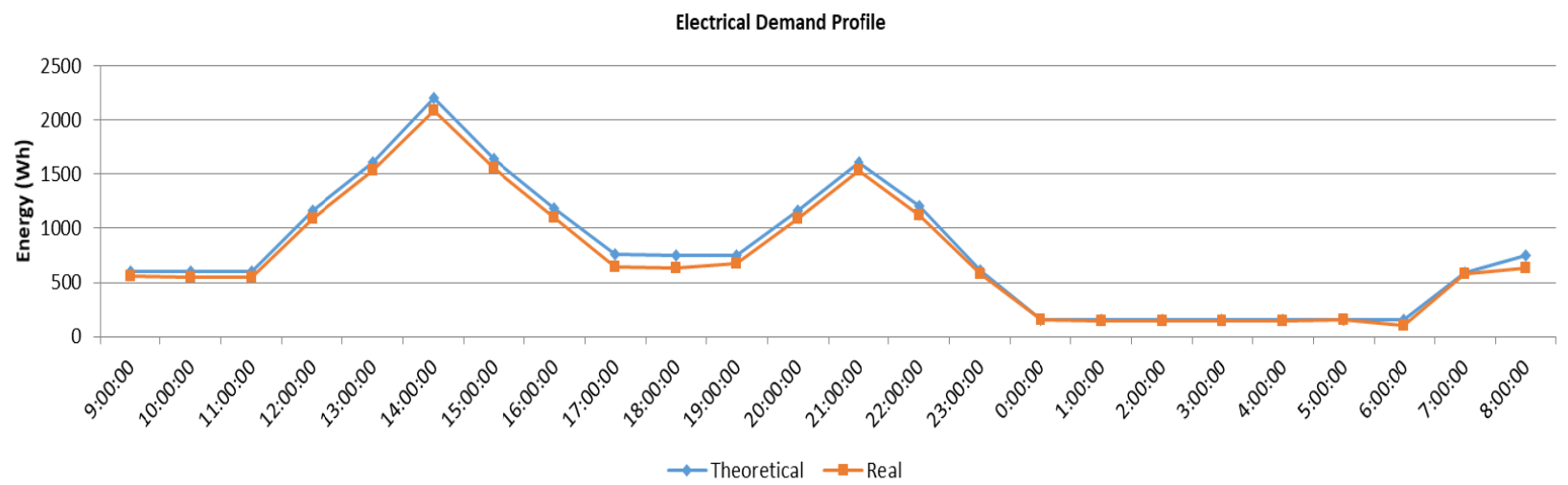

Fig. 4 Example of electrical demand. 


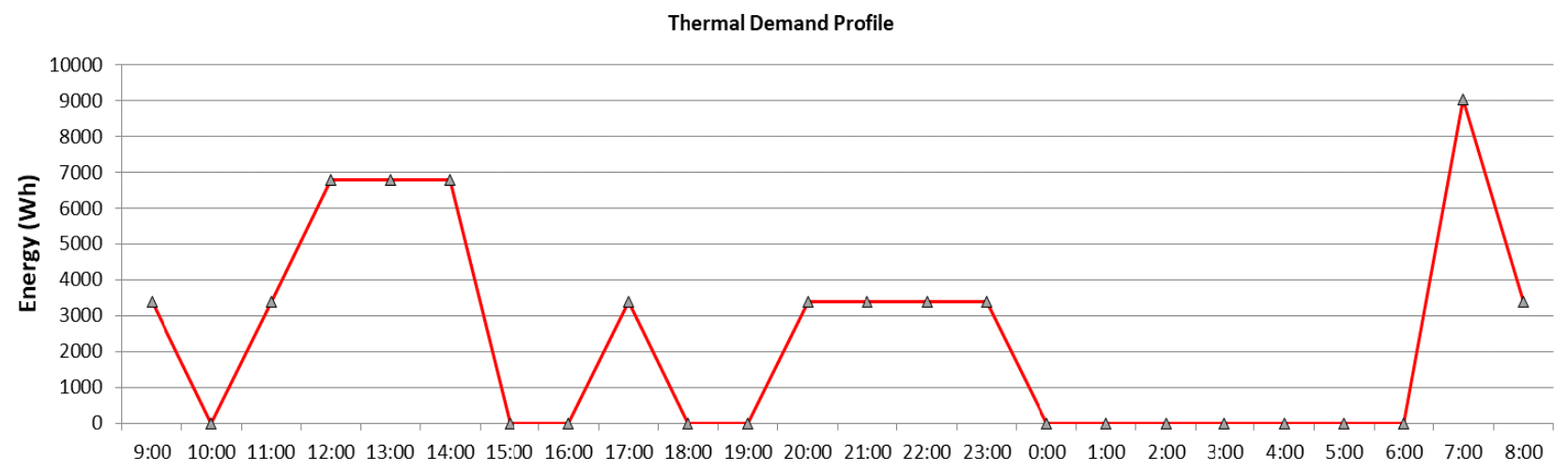

Fig. 5 Example of thermal demand.

$$
\begin{gathered}
\eta_{s}=\frac{\text { Produced Energy }\left(\varepsilon_{p}\right)}{\text { Solar Radiation }\left(\varepsilon_{\text {rad }}\right)+\operatorname{Gas} \text { energy }\left(\varepsilon_{\text {gas }}\right)} \\
\eta_{s n}=\frac{\text { System net efficiency }\left(\eta_{\mathrm{sn}}\right)}{\text { Solar Radiation }\left(\varepsilon_{\text {rad }}\right)+\text { Gas energy }\left(\varepsilon_{\text {gas }}\right)}
\end{gathered}
$$

Reduction in $\mathrm{CO}_{2}$ emissions $\left(\mathrm{CO}_{2 \mathrm{r}}\right)$

$$
\mathrm{CO}_{2 r}=
$$

System emissions $\left(\mathrm{CO}_{2 S}\right)-$

Network emissions $\left(\mathrm{CO}_{2 N S}\right)$

Network emissions are the mean emission for the Spanish electrical system, with different production systems and energy sources: coal, gas, nuclear and renewable. In 2017, the emission factor in Spanish Public System was $0.287 \mathrm{kgCO}_{2} / \mathrm{kWh}$.

With these conditions: demand and solar production, the Stirling engine starts when the storage levels are minimum in the flow chart. For this climate, the Stirling engine normally stars for electrical demand; if in this case water storage temperature passes the security value $\left(70{ }^{\circ} \mathrm{C}\right)$, the control system activates the consumption of heat to decrease this value.

\section{Results}

The results presented show the analysis on a half-overcast day (06/03/18) in Mediterranean climate. Average daily temperature $14.5^{\circ} \mathrm{C}$ and an energy balance are shown in Table 2 in Wh.

In this day, the electric energy balance is shown in Fig. 6. In this, the positive zone is production and the negative is consumption. In this day, consumption was higher than production because battery charge is lower at the end $(38 \%)$ than in the start $(96 \%)$, but this energy was also produced by the system other day (before or after).

The same concepts are used in Fig. 7 for thermal balance. In this case, it is possible that consumption is more than demand, because for security reasons if storage temperature reaches too high, automatic system consumes heat, but in this option, this heat is not considered in the net energy balance.

One particularity of this day is the necessity of Stirling engine use for electrical demand: the radiation is low. Fig. 8 shows this aspect and the use of electrical Stirling production for direct consumption or batteries charge. This state could be in hours with radiation (9.00) or without it (23.00). The type of use for Stirling energy depends much on demand as on battery charge.

\section{Discussion}

The analysed day could be considered as a day with almost maximum use of the Stirling engine and minimum solar production. It is interesting because it shows the system's capacity to cover this demand with a minimal solar power production. On the other hand, the case is an example of minimum $\mathrm{CO}_{2}$ emissions reduction. In these conditions, the main parameters are shown in Table 3.

In these conditions, the $\mathrm{CO}_{2}$ emissions reduction is $25.90 \%$, this value marks close to the minimum of the system on the contrary in sunny days it rises $100 \%$, in 
Table 2 Energy balance of a half-overcast day.

\begin{tabular}{ll}
\hline Energy balance $(\mathrm{Wh})$ & \\
\hline Solar radiation & 46,236 \\
PV energy & 4,997 \\
Solar Thermal energy & 1,017 \\
Solar energy produced & 6,014 \\
Gas energy consumed & 94,186 \\
Stirling energy produced & 81,000 \\
Produced energy & 87,014 \\
Used energy & 90,352 \\
\hline
\end{tabular}

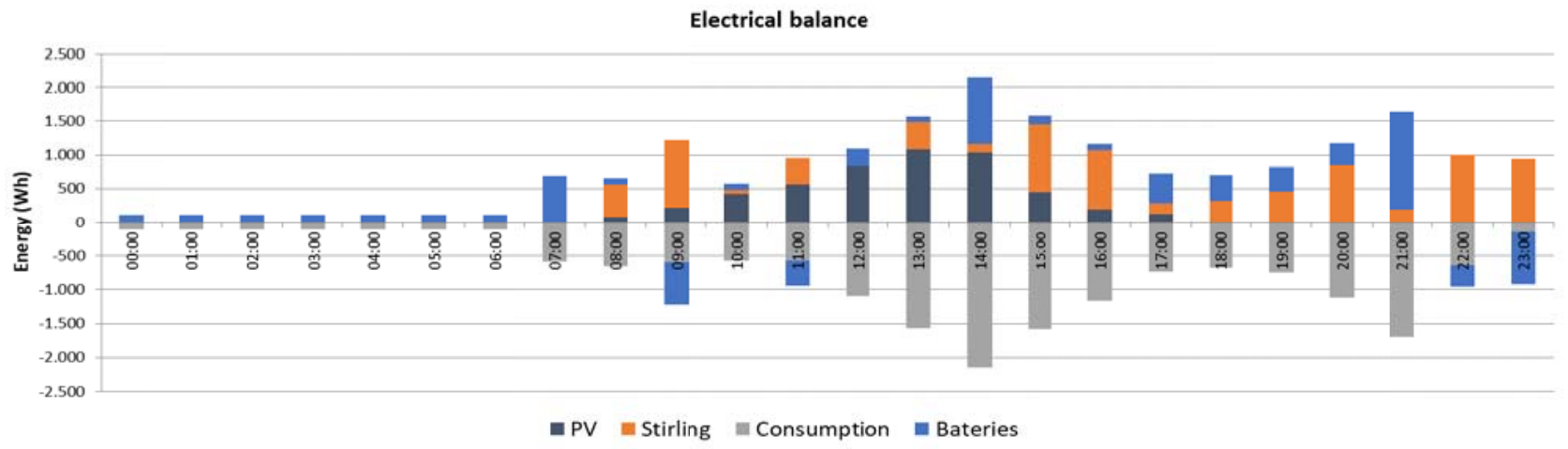

Fig. 6 Example of electrical balanced.

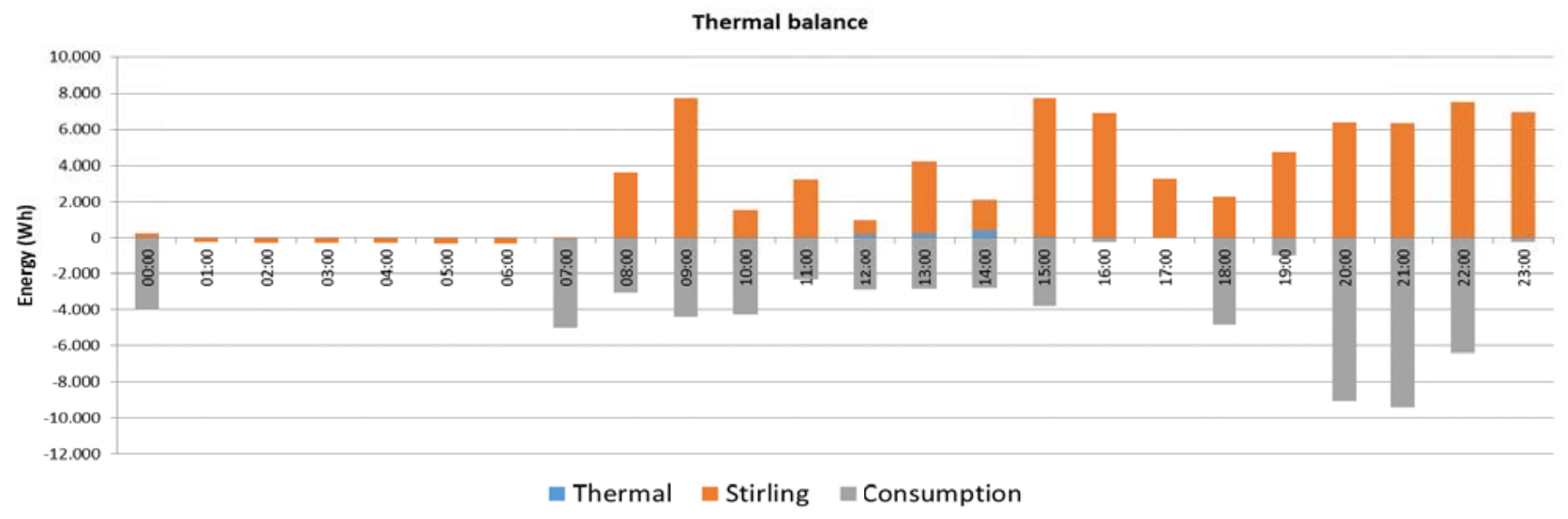

Fig. 7 Example of thermal balance.

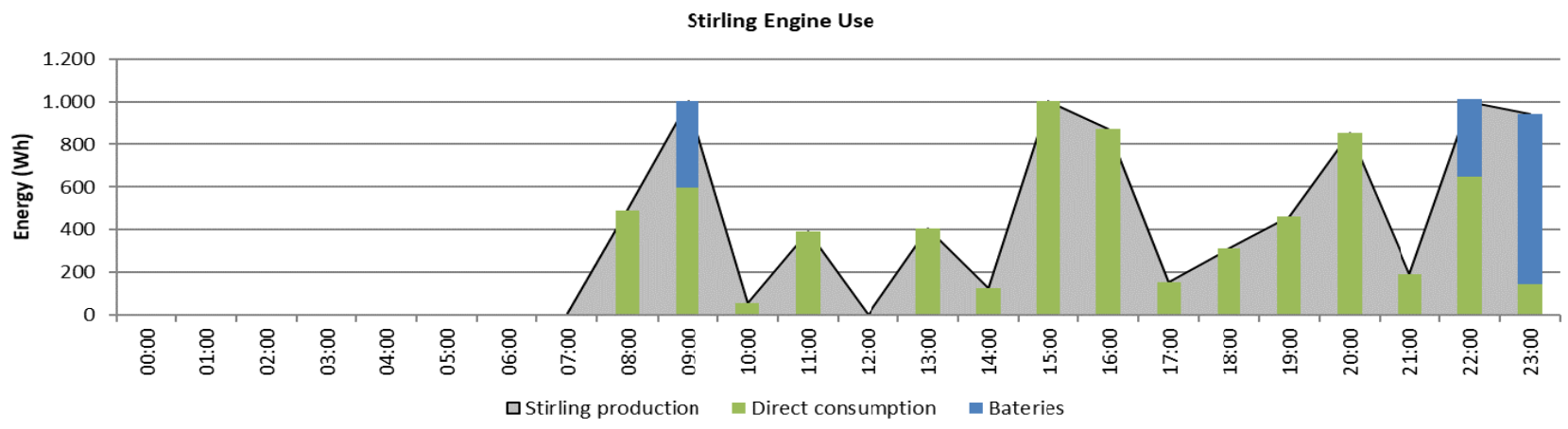

Fig. 8 Stirling engine use. 
Table 3 System balance.

\begin{tabular}{llll}
\hline Energy production $(\mathrm{Wh})$ & \multicolumn{3}{c}{ Energy balance } \\
\hline Solar radiation & 46,236 & $\mathrm{CO}_{2}$ emissions $(\mathrm{kg})$ & 19.21 \\
PV energy & 4,977 & Equivalent network $\mathrm{CO}_{2}$ emissions $(\mathrm{kg})$ & 25.93 \\
Solar thermal Energy & 1,017 & Reduction $\mathrm{CO}_{2}$ & $25.90 \%$ \\
Total solar energy produced & 6,014 & Stirling efficiency & 0.86 \\
Gas energy consumption & 94,186 & PV efficiency & 0.11 \\
Stirling energy produced & 81,000 & Thermal efficiency & 0.02 \\
Total energy produced & 87,014 & System efficiency & 0.62 \\
Used energy & 90,352 & Net system efficiency & 0.64 \\
& & & \\
\hline
\end{tabular}

other words, Stirling engine is not necessary in sunny days, but it can cover the demand in overcast days. For the same reasons, the values for solar systems efficiency are very close to their worth values: overcast and cold day, $2 \%$ for thermal system and $11 \%$ for PV system.

Special circumstances of this day produce that the used energy $(90,352 \mathrm{Wh})$ was more than the energy produced $(87,014 \mathrm{Wh})$. This is possible with the storage system: at the end of this day, storage level was less than in the start of the day in one or both systems.

\section{Conclusions}

A microcogeneration system with solar energy (PV and thermal) behaviour is analyzed in this work. The results show that this system has capacity to cover energy demand, electrical and thermal, for a house with different demand profiles in both types of energy.

The system could covert $100 \%$ of energy not independently of the weather, in sunny days practically $100 \%$ with solar energy and in overcast days with Stirling support and storage system. Electrical storage is a lithium battery LG Chem Resu $10 \mathrm{Li}$-Io with a capacity of $8.8 \mathrm{kWh}$ and thermal storage has a capacity of $300 \mathrm{~L}$.

The $\mathrm{CO}_{2}$ emissions reduction respect Spanish network emissions is from $25 \%$ in overcast days to $100 \%$ in sunny days, Stirling engine uses natural gas to work, and Spanish network is a mix of sources: coal, natural gas, nuclear and renewable with and official average emissions of $0.287 \mathrm{~kg} / \mathrm{kWh}$.
The composition of the system is: $21.2 \mathrm{~m}^{2} \mathrm{PV}$ panels surface, $3.54 \mathrm{~m}^{2}$ collector area of thermal panels, one Stirling engine Whispergen EU1 and storage systems allow an energy supply system with capacity for works unplugged to the network and cover $100 \%$ of demand in different weather conditions.

\section{Acknowledgements}

This work has been supported by the University of Málaga, the Ministry of Education, Culture and Sport, and by the project P11-RNM-7115 of the Junta de Andalucía, Spain.

\section{References}

[1] Gonzalez-Pino, I., Campos-Celador, A., Perez-Iribarren, E., et al. 2014. "Parametric Study of the Operational and Economic Feasibility of Stirling Micro-cogeneration Devices in Spain." Presented at the 3rd International Conference Integration of Microgeneration and Related Energy Technologies in Buildings Naples, Italy.

[2] Gonzalez-Pino, I., Perez-Iribarren, E., Campos-Celador, A., et al. 2015. "Influence of the Regulation Framework on the Feasibility of a Stirling Engine-Based Residential Micro-CHP Installation.” Energy 84: 575-88.

[3] Valenti, G., Silva, P., Fergnani, N., Di Marcoberardino, G., Campanari, S., and Macchi, E. 2014. "Experimental and Numerical Study of a Micro-cogeneration Stirling Engine for Residential Applications." Energy Procedia 45: 1235-44.

[4] Wakui, T., and Yokoyama, R. 2015. "Optimal Structural Design of Residential Cogeneration Systems in Consideration of Their Operating Restrictions." Energy 64: 106-20.

[5] Malliotakis, E., Vourliotakis, G., Marin, R., Vicente, A., Giannopoulos, D., Founti, M., Zach, J., and Starosielec, B. 
2014. "Performance Monitoring of Stirling CHP Units in an Industrial District in Poland." Presented at International Stirling Engine Committee, Bilbao.

[6] Karmacharya, S., Putrus, G., Underwood, C. P., Mahkamov, K., McDonald S., and Alexakis, A. 2014. "Simulation of Energy Use in Buildings with Multiple Micro-generators." Applied Thermal Engineering 62 (2): 581-92.

[7] Acevedo, L., Uche, J., Martinez, A., Bayod-Rújula, A. A., and Del-Amo, A. 2017. "Trigeneration for Domestic Purposes in Isolated Areas Based on Hybrid RES." Presented at International Conference on Renewable Energies and Power Quality (ICREPQ'17), Malaga, Spain.

[8] Iwaszkiewicz, J., Perz, J., and Mikielewicz, C. J. 2009.
"A Practical Approach to the Cogeneration System for Rural Appliances." Presented at International Conference on Renewable Energies and Power Quality (ICREPQ'09), Valencia, Spain.

[9] Schuster, T. 2009. "Design and Operation of a Local Cogeneration Plant Supplying a Multi-family House." Presented at International Conference on Renewable Energies and Power Quality (ICREPQ'09), Valencia, Spain.

[10] Dondas, M., Alkhalil, F., Degobert, P., Colas, F., and Robyns, B. 2009. "Fuel Consumption Minimization of a Cogeneration System Multi Machines Associated with a Photovoltaic." Presented at International Conference on Renewable Energies and Power Quality (ICREPQ'09), Valencia, Spain. 